УДК 535.34:666.32:537.531

DOI: $10.17308 / \mathrm{kcmf} .2019 .21 / 1155$

Поступила в редакцию 05.06.2019

Подписана в печать 15.08.2019

\title{
ИНФРАКРАСНАЯ СПЕКТРОСКОПИЯ КАК МЕТОД ОПРЕДЕЛЕНИЯ СТРУКТУРНЫХ ОТКЛИКОВ ПРИРОДНЫХ ГЛИН НА СВЧ-ВОЗДЕЙСТВИЕ
}

\author{
(c) 2019 А. Г. Четверикова ${ }^{\bowtie}$, О. Н. Каныгина, г. Ж. Алпысбаева, А. А. Юдин, С. С. Сокабаева \\ Оренбургский государственный университет \\ просп. Победы, 13, 460018 Оренбург, Российская Федерация
}

\begin{abstract}
Аннотация. Методом ИК-спектроскопии изучены структурные отклики частиц монтмориллонитовой и каолинитовой глин месторождений Оренбургской области на СВЧ-воздействие. Обработку проб в течение 10 минут проводили в поле магнетрона мощностью 750 Вт в воздушной и влажной средах. Спектры получены с помощью ИК-Фурье спектрометра в диапазоне длин волн 4000-400 $\mathrm{cm}^{-1}$. Установлено, что в монтмориллонитовой глине количество доминирующих связей в тетраэдре $\mathrm{SiO}_{4}$ снижается в 1.5 раза при обработке в сухом воздухе и в 1.8 раза - во влажном. В глине, содержащей каолинит, все типы связей активно разрушаются под воздействием СВЧ-поля.
\end{abstract}

Ключевые слова: инфракрасная спектроскопия, полоса поглощения, монтмориллонит, каолинит, филлосиликаты, СВЧ-воздействие, химические связи.

\section{ВВЕДЕНИЕ}

В основе контроля структурно-морфологических изменений при обработке природных алюмосиликатов микроволновым излучением лежит метод ИК-спектроскопии. Он позволяет с удовлетворительной степенью надежности оценивать разнообразие в типе и характере связей в структурных элементах, составляющих дисперсные частицы природных глинистых минералов. ИК-спектры отражают значения энергии молекулярных группировок, различия в которых дают характерные для каждой группы полосы поглощения [1, 2].

Ранее в работе [3] с помощью оптической микроскопии и фрактального формализма нами исследованы отклики фазовой морфологии природных оренбургских глин на СВЧ-воздействие. Установлена корреляция между временем воздействия СВЧ-излучения на дисперсную глинистую систему, состоящую из частиц природной глины, и двухэтапным характером агломерации частиц, описываемой моделями DCA и ССА [4]. Показано, что степень морфологической эволюции частиц пропорциональна времени воздействия СВЧ излучения.

С помощью рентгеноструктурного анализа установлено наличие фазовых и полиморфных пре-

\footnotetext{
$\triangle$ Четверикова Анна Геннадьевна, e-mail: KR-727@mail.ru
}

вращений, происходящих во время воздействия микроволнового поля. Оксиды алюминия и кремния претерпевают полиморфные превращения: часть глинозема превращается в корунд $\alpha-\mathrm{Al}_{2} \mathrm{O}_{3}$. На характер полиморфных превращений в диоксиде кремния влияет внешняя среда: в воздушной среде формируются $\beta$-кварц и $\beta$-кристобалит, а во влажной среде - только $\beta$-кварц. В обеих средах наблюдается активный процесс превращения гематита $\mathrm{Fe}_{2} \mathrm{O}_{3}$ в магнетит $\mathrm{FeO} \cdot \mathrm{Fe}_{2} \mathrm{O}_{3}$ [5].

Авторами [6] приводится достаточное количество данных, указывающих на то, что свойства слоистых алюмосиликатов различных месторождений существенно отличаются от свойств эталонных представителей этих минералов. Это свидетельствует о важности оценки влияния внешних воздействий на кристаллографические особенности и ИК-спектры глин конкретных месторождений.

Поэтому мы перешли к изучению межатомных связей в глинах Оренбургской области, содержащих каолинит и монтмориллонит, подвергнутых СВЧ-воздействию. Результаты исследований свидетельствуют о возможности инициирования процессов структурных изменений в дисперсных глинистых системах путем воздействия электромагнитного поля микроволнового диапазона [7].

Контент доступен под лицензией Creative Commons Attribution 4.0 License.

The content is available under Creative Commons Attribution 4.0 License. 
Целью настоящей работы является исследование эволюции межатомных связей под воздействием СВЧ-поля методом ИК-спектроскопии, идентификация мод спектров в глинах, содержащих монтмориллонит и каолинит с близкими химическими и различающимися фазовыми составами.

\section{ТЕОРЕТИЧЕСКАЯ ЧАСТЬ}

Каолинит представляет собой диоктаэдрический филлосиликат типа $1: 1$ с формулой $\mathrm{Al}_{2} \mathrm{Si}_{2} \mathrm{O}_{5}(\mathrm{OH})_{4}$. Известно, что этот тип глины является неорганическим полимером с двухмерной слоистой структурой. В каждом слое лист тетраэдров $\mathrm{SiO}_{4}$ связан на вершинах тетраэдра с листом октаэдров алюминия (III) четырьмя из шести октаэдрических точек, занятых гидроксильными группами. Два из каждых трех алюминиевых октаэдрических узлов заняты, что приводит к искажению решетки, понижению симметрии кристалла. Непосредственным результатом низкой симметрии является богатый ИК-спектр каолинита [8]. Монтмориллониты представляют собой тип диоктаэдрических филлосиликатов (2:1) с общей формулой $\mathrm{Al}_{(2-y)} \mathrm{M}_{y} \cdot \mathrm{Si}_{(4-x)} \mathrm{Al}_{x} \cdot \mathrm{O}_{10}(\mathrm{OH})_{2} \mathrm{M}_{(x+y)} \cdot \mathrm{nH}_{2} \mathrm{O}$, где $\mathrm{y}>\mathrm{x}, \mathrm{a}$ М представляет межслойные обменные катионы. Эти глины являются в некоторой степени турбостратическими [8], набухают и обладают значительной способностью обмениваться межслоевыми катионами.

В спектрах глин обычно наблюдаются широкие полосы в области $3700-3600 \mathrm{~cm}^{-1}$, соответствующие валентным асимметричным и симметричным колебаниям ОН-связей [9]. Для силикатов, содержащих ОН-группы, в спектре обычно обнаруживаются полосы в области $1200-800 \mathrm{~cm}^{-1}$, которые относятся к валентным $\mathrm{Si}-\mathrm{O}$ и $\mathrm{Si}-\mathrm{O}-\mathrm{Si}$ связям в различных кремнекислородных радикалах [10]. Наиболее существенным признаком замещения Al-Si в соединениях, где имеет место увеличение доли замещения кремния алюминием в тетраэдрической позиции, является изменение основной $\mathrm{Si}-\mathrm{O}$ полосы в области 1100-900 $\mathrm{cm}^{-1}$, появление относительно слабых полос в области $800-750 \mathrm{~cm}^{-1}$ и увеличение диффузности полос в области 500-
$400 \mathrm{~cm}^{-1}$. Таким образом, изоморфное упорядоченное взаимозамещение катионов сложного аниона приводит к смещению и изменению интенсивностей полос спектра поглощения исследуемых минералов [10].

\section{ЭКСПЕРИМЕНТАЛЬНАЯ ЧАСТЬ}

Объекты исследования представляли собой порошки природных глин месторождений Оренбургской области, содержащих каолинит (K) и монтмориллонит (М). В табл. 1 представлены химические составы исследуемых глин, определенные по методикам силикатного анализа [11].

Анализ значений в табл. 1 показывает, что $\mathrm{SiO}_{2}$ и $\mathrm{Al}_{2} \mathrm{O}_{3}$ являются основными компонентами глин. Массовое содержание $\mathrm{SiO}_{2}$ и $\mathrm{Al}_{2} \mathrm{O}_{3}$ составляло, \%: примерно 56 и 19 для глины М, и 57.5 и 11 - для глины К соответственно. Согласно результатам рентгеноструктурного исследования изученные глины содержат достаточное количество глинистых минералов, в основном каолинита и монтмориллонита (более $50 \%$ ). Обе глины М и К отличаются высоким содержанием оксида железа, \%: 9.5 и 4.9 соответственно. Что касается содержания компонентов $\mathrm{Na}_{2} \mathrm{O}, \mathrm{K}_{2} \mathrm{O}$, $\mathrm{MgO}$ и $\mathrm{TiO}_{2}$, глины имеют близкие показатели. Потеря веса на 7.1 (М) и 9.6 (К) \%, вероятно, связана с уходом координированной воды, гидроксидов и органических веществ при прокаливании выше $900{ }^{\circ} \mathrm{C}$.

Исходные порошковые пробы (М0 и К0), состоящие из частиц глинистых минералов размерами $d \leqslant 630 \mu \mathrm{m}$, в течение 10 минут подвергали воздействию микроволнового излучения мощностью 750 W в двух режимах. Пробы М1 и К1 получали СВЧ-обработкой в сухом воздухе с относительной влажностью менее 30 \%, при этом температура в объеме порошков достигла $200{ }^{\circ} \mathrm{C}$. В среде водяного пара (влажность более 80\%), температура образцов М2 и К2 достигла $400{ }^{\circ} \mathrm{C}$.

Изменения химических связей в глинах оценивали, используя ИК-спектры перечисленных проб, запрессованных в таблетки $\mathrm{KBr}$, записанные с помощью ИК-Фурье спектрометра Bruker Alpha. Он предназначен для измерения оптических спектров пропускания и отражения в средней области ИК-диапазона $4000-400 \mathrm{~cm}^{-1}$. Pе-

Таблица 1. Химические составы глин, содержащих монтмориллонит (М) и каолинит (К)

[Table 1. Chemical compositions of clays containing montmorillonite (M) and kaolinite (K)]

\begin{tabular}{|c|c|c|c|c|c|c|c|c|c|c|}
\hline Clay & $\begin{array}{c}\text { П.П.П. } \\
{[\mathrm{LOI}]}\end{array}$ & $\mathrm{SiO}_{2}$ & $\mathrm{Fe}_{2} \mathrm{O}_{3}$ & $\mathrm{TiO}_{2}$ & $\mathrm{Al}_{2} \mathrm{O}_{3}$ & $\mathrm{CaO}$ & $\mathrm{MgO}$ & $\mathrm{Na}_{2} \mathrm{O}$ & $\mathrm{K}_{2} \mathrm{O}$ & $\sum, \%$ \\
\hline $\mathrm{M}$ & 7,08 & 55,90 & 9,51 & 0.86 & 18,63 & 0.72 & 2,05 & 1,90 & 3,24 & 99,89 \\
\hline $\mathrm{K}$ & 9,61 & 57,46 & 4,90 & 0.53 & 11,00 & 8,21 & 2,93 & 2,04 & 3,04 & 99,72 \\
\hline
\end{tabular}


гистрация ИК-спектров на отражение производилась методикой НПВО - нарушенного полного внутреннего отражения. Достоинствами фурье-спектрометрии являются высокое отношение сигнал/шум, возможность работы в широком диапазоне длин волн без смены диспергирующего элемента, быстрая регистрация спектра и высокая разрешающая способность (до $0.001 \mathrm{~cm}^{-1}$ ). Для исключения систематических погрешностей при эксперименте использовали запись всех спектров во всем диапазоне длин волн.
РЕЗУЛЬТАТЫ И ИХ ОБСУЖДЕНИЕ

Общие виды ИК-спектров образцов глин, содержащих монтмориллонит и каолинит, представлены на рис. $1 a$ и $1 b$ соответственно. Сплошной линией изображены спектры глин в исходном состоянии, пунктирными - после СВЧ-обработки на воздухе.

Основные полосы поглощения с соответствующими отнесениями приведены в табл. 2 и 3.

Полоса $3700 \mathrm{~cm}^{-1}$ (в М-глине, рис. 1a) свидетельствует о наличии внутриповерхностных ОН-
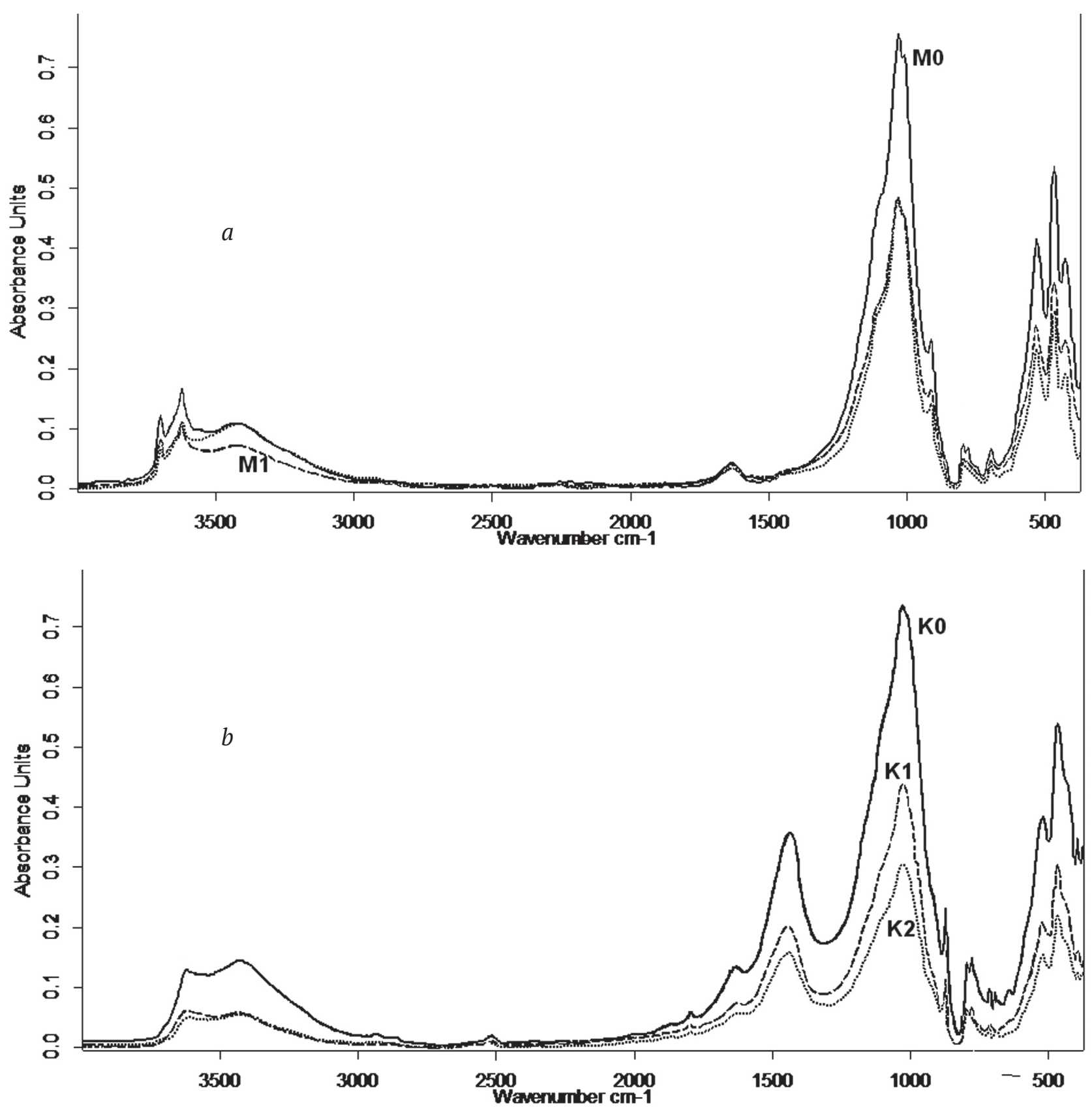

Рис. 1. ИК-спектры исследуемых образцов глин, содержащих: монтмориллонит (a) и каолинит (b) [Fig. 1. General view of the FTIR spectra of the studied clays containing: montmorillonite $(a)$ and kaolinite $(b)$ ] 
Таблица 2. Характеристические моды межатомных связей в образцах серии М в исходном состоянии и после СВЧ-воздействия

[Table 2. Characteristic modes of interatomic bonds in M-samples in the initial state and after MW-exposure]

\begin{tabular}{|c|l|c|c|c|}
\hline \multirow{2}{*}{$\mathrm{cm}^{-1}$} & \multicolumn{1}{|c|}{$\begin{array}{c}\text { Отнесение полос поглощения } \\
\text { [Assignment of absorption bands] }\end{array}$} & \multicolumn{3}{c|}{$\begin{array}{c}\text { I, отн.ед. } \\
\text { [I, abs. unit] }\end{array}$} \\
\cline { 3 - 5 } & \multicolumn{1}{|c|}{} & $\mathrm{M} 0$ & $\mathrm{M} 1$ & $\mathrm{M} 2$ \\
\hline 3700 & $v_{\mathrm{as}}(\mathrm{O}-\mathrm{H})$ & 0.16 & 0.10 & 0.09 \\
\hline 3621 & $v_{\mathrm{s}}(\mathrm{O}-\mathrm{H})$ & 0.21 & 0.14 & 0.14 \\
\hline 3424 & $\mathrm{v}(\mathrm{O}-\mathrm{H})$ & 0.14 & 0.09 & 0.14 \\
\hline 1635 & $\mathrm{v}(\mathrm{H}-\mathrm{O}-\mathrm{H})$ & 0.02 & 0.02 & 0.02 \\
\hline 1032 & $v_{\text {as }}(\mathrm{Si}-\mathrm{O}-\mathrm{Si})_{\text {bend }}$ or $v(\mathrm{Si}-\mathrm{O}-\mathrm{Al})$ & 1.00 & 0.63 & 0.63 \\
\hline 1009 & $v_{s}(\mathrm{Si}-\mathrm{O}-\mathrm{Si})_{\text {bend }}$ or $v(\mathrm{Si}-\mathrm{O}-\mathrm{Al})$ & 0.80 & 0.60 & 0.60 \\
\hline 912 & $(\mathrm{Al}-\mathrm{O}-\mathrm{H})$ & 0.33 & - & 0.19 \\
\hline 873 & $v(\mathrm{Si}-\mathrm{O}), v(\mathrm{Si}-\mathrm{O}-\mathrm{Si}), v(\mathrm{Al}-\mathrm{O}), v(\mathrm{Al}-\mathrm{O}-\mathrm{H})$ & 0.05 & 0.05 & 0.05 \\
\hline 797 & $v_{\mathrm{s}}(\mathrm{Si}-\mathrm{O}-\mathrm{Si})$ in the $\mathrm{SiO} \mathrm{O}_{4}$ tetrahedron & 0.08 & 0.06 & 0.05 \\
\hline 713 & $v_{\mathrm{s}}(\mathrm{Si}-\mathrm{O}-\mathrm{Al})$ & 0.02 & 0.02 & 0.01 \\
\hline 694 & $v(\mathrm{Al}-\mathrm{O})$ in $\alpha-\mathrm{Al}_{2} \mathrm{O}_{3}, \delta(\mathrm{Si}-\mathrm{O}-\mathrm{Al})$ & 0.09 & 0.06 & 0.03 \\
\hline 533 & $\mathrm{Fe}-\mathrm{O}$ in $\alpha-\mathrm{Fe}_{2} \mathrm{O}_{3}, \delta(\mathrm{Si}-\mathrm{O})$ in the $\mathrm{SiO}_{4}$ tetrahedron & 0.49 & 0.33 & 0.28 \\
\hline 467 & $\delta(\mathrm{Si}-\mathrm{O})$ in the $\mathrm{SiO}_{4}$ tetrahedron, $v(\mathrm{C}-\mathrm{C})$ & 0.64 & 0.41 & 0.35 \\
\hline 428 & $\mathrm{Fe}-\mathrm{O}$ in $\alpha-\mathrm{Fe}_{2} \mathrm{O}_{3}, \delta(\mathrm{Si}-\mathrm{O}), \delta\left(\mathrm{Si}-\mathrm{O}-\mathrm{Fe}^{2+}\right)$ & 0.46 & 0.29 & 0.23 \\
\hline
\end{tabular}

Таблица 3. Характеристические моды межатомных связей в образцах серии $\mathrm{K}$ в исходном состоянии и после СВЧ-воздействия

[Table 3. Characteristic modes of interatomic bonds in K-samples in the initial state and after MW-exposure ]

\begin{tabular}{|c|c|c|c|c|}
\hline \multirow[t]{2}{*}{$\mathrm{cm}^{-1}$} & \multirow{2}{*}{$\begin{array}{l}\text { Отнесение полос поглощения } \\
\text { [Assignment of absorption bands] }\end{array}$} & \multicolumn{3}{|c|}{$\begin{array}{l}\text { I, отн.ед. } \\
\text { [I, abs. unit] }\end{array}$} \\
\hline & & K0 & $\mathrm{K} 1$ & $\mathrm{~K} 2$ \\
\hline 3621 & $\mathrm{v}_{\mathrm{as}}(\mathrm{O}-\mathrm{H})$ & 0.16 & 0.08 & 0.06 \\
\hline 3424 & $v_{s}(\mathrm{O}-\mathrm{H})$ & 0.19 & 0.07 & 0.07 \\
\hline 1638 & $\delta(\mathrm{H}-\mathrm{O}-\mathrm{H})$ & 0.2 & 0.10 & 0.09 \\
\hline 1435 & $v(\mathrm{O}-\mathrm{H})$ & 0.49 & 0.30 & 0.21 \\
\hline 1032 & $v_{\text {as }}(\mathrm{Si}-\mathrm{O}-\mathrm{Si})_{\text {bend }}$ or $v(\mathrm{Si}-\mathrm{O}-\mathrm{Al})$ & 1.00 & 0.60 & 0.41 \\
\hline 1008 & $v_{s}(\mathrm{Si}-\mathrm{O}-\mathrm{Si})_{\text {bend }}$ or $v(\mathrm{Si}-\mathrm{O}-\mathrm{Al})$ & 0.85 & 0.41 & 0.32 \\
\hline 912 & $\delta(\mathrm{Al}-\mathrm{O}-\mathrm{H})$ & 0.33 & - & - \\
\hline 873 & $v(\mathrm{Si}-\mathrm{O}), v(\mathrm{Si}-\mathrm{O}-\mathrm{Si}), v(\mathrm{Al}-\mathrm{O}), v(\mathrm{Al}-\mathrm{O}-\mathrm{H})$ & 0.31 & 0.15 & 0.13 \\
\hline 797 & $v_{\mathrm{s}}(\mathrm{Si}-\mathrm{O}-\mathrm{Si})$ in the $\mathrm{SiO}_{4}$ tetrahedron & 0.17 & 0.07 & 0.06 \\
\hline 778 & $v_{s}(\mathrm{Si}-\mathrm{O}), \mathrm{H}-\mathrm{O}-\mathrm{Fe}^{3+}$ & 0.18 & 0.08 & 0.06 \\
\hline 713 & $v_{s}(\mathrm{Si}-\mathrm{O}-\mathrm{Al})$ & 0.12 & 0.05 & 0.04 \\
\hline 694 & $v(\mathrm{Al}-\mathrm{O})$ in $\alpha-\mathrm{Al}_{2} \mathrm{O}_{3}, \delta(\mathrm{Si}-\mathrm{O}-\mathrm{Al})$ & 0.11 & 0.04 & 0.04 \\
\hline 520 & $\mathrm{Fe}-\mathrm{O}$ in $\alpha-\mathrm{Fe}_{2} \mathrm{O}_{3}, \delta(\mathrm{Si}-\mathrm{O})$ in the $\mathrm{SiO}_{4}$ tetrahedron & 0.47 & 0.26 & 0.18 \\
\hline 467 & $\delta(\mathrm{Si}-\mathrm{O})$ in the $\mathrm{SiO}_{4}$ tetrahedron, $v(\mathrm{C}-\mathrm{C})$ & 0.66 & 0.37 & 0.27 \\
\hline 428 & $\mathrm{Fe}-\mathrm{O}$ in $\alpha-\mathrm{Fe}_{2} \mathrm{O}_{3}, \delta(\mathrm{Si}-\mathrm{O}), \delta\left(\mathrm{Si}-\mathrm{O}-\mathrm{Fe}^{2+}\right)$ & 0.54 & 0.28 & 0.21 \\
\hline
\end{tabular}


групп, расположенных на поверхностях октаэдрических слоев напротив тетраэдрических кислородов. Полосу $3621 \mathrm{~cm}^{-1}$ (в обеих глинах) можно отнести к внутренним ОН-группам, расположенным в плоскости, общей для октаэдрических и тетраэдрических слоев. ОН-валентная полоса с максимумом $3424 \mathrm{~cm}^{-1}$ и более слабая полоса для деформационных колебаний $1640 \mathrm{~cm}^{-1}$ отнесены к молекулам воды во внешних координационных сферах обменных катионов. Наличие моды $1640 \mathrm{~cm}^{-1}$ объясняется колебаниями ОН-групп молекул межслойной воды, присутствующих в глине [12]. Наличие обеих полос зачастую объясняется поглощением глиной воды из атмосферы [13].

Анализ приведенных ИК-спектров показывает, что основные полосы на них относятся к валентным связям кремния с кислородом и водорода с кислородом. Полоса поглощения 1435 $\mathrm{cm}^{-1}$, соответствующая деформационным колебаниям групп $\mathrm{OH}^{-}$в вершинах кремнекислородных тетраэдров, является отличительной особенностью каолинитов. Атомы кислорода могут быть связаны с двумя атомами кремния мостиковыми связями $\mathrm{Si}-\mathrm{O}-\mathrm{Si}$, или с одним - немостиковыми связями $\mathrm{Si}-\mathrm{O}$. В частности, полосы $1032 \mathrm{~cm}^{-1}$ и $1009 \mathrm{~cm}^{-1}$ приписываются валентным колебаниям мостиковых связей $\mathrm{Si}-\mathrm{O}-\mathrm{Si}(\mathrm{Al})$ в кристаллической решетке [2].

При частичном замещении кремния в решетке большинство валентных полос слоистых минералов (1000-900 cm-1) перемещается по направлению к низким частотам [14]. Появление полос поглощения в области $1000-900 \mathrm{~cm}^{-1}$ может быть связано с валентными колебаниями немостиковых связей $\mathrm{Si}-\mathrm{O}$ в различных силикатных и алюмосиликатных группировках, а также в простых орто- и диортосиликатных анионах в аморфной фазе.

Алюминий находится в алюмосиликатах либо в тетраэдрической координации, либо в октаэдрической. Для $\alpha-\mathrm{Al}_{2} \mathrm{O}_{3}$ закономерно обнаруживаются валентные колебания Al-O в области 1160 и $800 \mathrm{~cm}^{-1}$. Для диоктаэдрических структур, содержащих трехвалентные ионы $\mathrm{Al}^{3+}$ в октаэдрических позициях монтмориллонита обнаруживается другая ОН-полоса в области $1000-800 \mathrm{~cm}^{-1}$. Ее положение зависит от длины и силы металл-гидроксильной связи. Эту полосу относят к связи Al-O-H. В подобных филлосиликатах наличие очень слабой полосы $912 \mathrm{~cm}^{-1}$ объясняется проявлением деформационных колебаний немостиковой связи Al-O-H, которая гораздо длиннее и слабее связи $\mathrm{Si}-\mathrm{O}$.
Очень слабые полосы на $797 \mathrm{~cm}^{-1}$ и $694 \mathrm{~cm}^{-1}$ в пробах можно объяснить связями $\mathrm{Si}-\mathrm{O}-\mathrm{Si}$ (Al) в искаженных тетраэдрических и октаэдрических слоях. В частности, полоса в области $694 \mathrm{~cm}^{-1}$ относится к деформационным колебаниям $\mathrm{Si}-$ O-Si, включающим мостиковый кислород, а полоса $797 \mathrm{~cm}^{-1}$ - к валентным симметричным колебаниям $\mathrm{Si}-\mathrm{O}-\mathrm{Si}$, характерным для кремния в тетраэдре $\mathrm{SiO}_{4}$.

Для монтмориллонитов по мере увеличения содержания ионов Al в тетраэдрической позиции происходит рост интенсивности полос поглощения около $873 \mathrm{~cm}^{-1}$, появляются слабые полосы между 800 и $850 \mathrm{~cm}^{-1}$. Полосы поглощения в К-глине $520,467,428 \mathrm{~cm}^{-1}$ становятся более диффузными с небольшим изменением положения в спектре [10]. Полоса $428 \mathrm{~cm}^{-1}$ указывает на наличие колебаний $\mathrm{Fe}-\mathrm{O}$, отсутствие полосы при $621 \mathrm{~cm}^{-1}$ (характерной для фазы $\gamma-\mathrm{Fe}_{2} \mathrm{O}_{3}$ ) и, одновременно, появление полосы при $520 \mathrm{~cm}^{-1}$ может свидетельствовать о фазовом превращении $\gamma-\mathrm{Fe}_{2} \mathrm{O}_{3} \rightarrow \alpha-\mathrm{Fe}_{2} \mathrm{O}_{3}[12]$.

Во всех образцах в спектрах присутствовала полоса С-C (при $467 \mathrm{~cm}^{-1}$ ). Мода колебания не изменяется при обработке, но их интенсивность снижается, что может быть ответом как на ограничение угловых деформаций связи C-C путем удержания углерода между пластинками глинистых минералов, так и удаления его (выгорания) из объема глины [15].

\section{ЗАКЛЮЧЕНИЕ}

В обеих природных глинах доминируют связи типа $v_{\text {as }}(\mathrm{Si}-\mathrm{O}-\mathrm{Si})$ мост или $v(\mathrm{Si}-\mathrm{O}-\mathrm{Al})$ и связи $\delta(\mathrm{Si}-\mathrm{O})$ в тетраэдре $\mathrm{SiO}_{4}$ Полосы имеют практически одинаковые интенсивности, как и в случае связей типа $(\mathrm{O}-\mathrm{H})$. Остальные связи в каолиновой глине выражены сильнее (интенсивности полос больше в 3-5 раз). Полоса поглощения с волновым числом $1009 \mathrm{~cm}^{-1}$, отнесенная в работах $[16,9]$ к каолиниту, наблюдается в обеих глинах.

Воздействие СВЧ-излучения приводит к различным структурным изменениям в разных глинах. ИК-спектры образцов глины, содержащей монтмориллонит, в исходном состоянии (М0) и после воздействии СВЧ-поля, различаются, демонстрируя наличие структурных откликов. Мода, отнесенная к валентным симметричным колебаниям мостиковых связей, исчезла. Деформационная немостиковая связь Al-O-H (полоса $912 \mathrm{~cm}^{-1}$ ) разрушается после обработки СВЧ-излучением в сухом воздухе и появляется вновь во влажной среде, как и связь $\mathrm{Si}-\mathrm{O}-\mathrm{Si}$ (полоса $1009 \mathrm{~cm}^{-1}$ ). 
Интенсивность полос поглощения, отнесенных к валентным колебаниям связей $\mathrm{Si}-\mathrm{O}-\mathrm{Si}$ в тетраэдре $\mathrm{SiO}_{4}\left(797 \mathrm{~cm}^{-1}\right)$ и деформационным колебаниям связей $\mathrm{Si}-\mathrm{O}$ в тетраэдре $\mathrm{SiO}_{4}(533,467$, 428 уменьшается в 1.5 и 1.8 раз после СВЧ-обработки на воздухе и во влажной среде соответственно.

Инфракрасные спектры К-глины как и в работе [9] содержат характерные полосы поглощения, $\mathrm{cm}^{-1}: 3620,3424,1032,1008$ и 912. В ИК-спектре пробы К0 интенсивность полос поглощения выше, чем в спектре пробы М0, однако в результате воздействия СВЧ-поля большинство связей быстро разрушается: в воздухе их доля уменьшается примерно в 1.8-2 раза, а во влажной в 2.5 раза. Значительная часть доминирующих связей в тетраэдре $\mathrm{SiO}_{4}$, как и связь $\delta(\mathrm{Al}-\mathrm{O}-\mathrm{H})$, разрушается. Можно сделать вывод, что частицы каолиновой глины более чувствительны к условиям СВЧ-обработки.

Влажная среда при СВЧ-воздействии на монтмориллонитовую глину способствует восстановлению в ней связей типа $\mathrm{Si}-\mathrm{O}-\mathrm{Si}, \mathrm{Si}-\mathrm{O}-\mathrm{Al}$ и $\mathrm{Al}-\mathrm{O}-\mathrm{H}$. В результате обработки СВЧ излучением структурные связи в каолиновой глине разрушаются, а в монтмориллонитовой - могут перегруппировываться. Поэтому после СВЧ-воздействия авторы [7] в монтмориллонитовой глине наблюдали агломерацию частиц, в а каолинитовой - нет. Варьируя режимы внешнего воздействия, можно вызывать структурные изменения в природных глинах.

\section{ИСТОЧНИК ФИНАНСИРОВАНИЯ}

Работа выполнена при финансовой поддержке РФФИ и правительства Оренбургской области в рамках научного проекта № 19-43560001 р_а «Физико-химические принципы процессов СВЧ-консолидации каолинитов».

\section{КОНФЛИКТ ИНТЕРЕСОВ}

Авторы декларируют отсутствие явных и потенциальных конфликтов интересов, связанных с публикацией настоящей статьи.

\section{СПИСОК ЛИТЕРАТУРЫ}

1. Домашевская Э. П., Буйлов Н. С., Лукин А. Н., Ситников А. В. Исследование межатомного взаимодействия в многослойных наноструктурах $\left[(\mathrm{CoFeB}) 60 \mathrm{C} 40 / \mathrm{SiO}_{2}\right] 200$ и $\left[(\mathrm{CoFeB}) 34\left(\mathrm{SiO}_{2}\right) 66 / \mathrm{C}\right] 46$ с композитными металлсодержащими слоями методом ИК-спектроскопии // Неорганические материалы, 2018, т. 54(2), с. 153-159. DOI: 10.7868/ S0002337X18020069
2. Четверикова, А. Г., Маряхина В. С. Исследования полиминеральной глины, содержащей трехслойные алюмосиликаты физическими методами // Вестник Оренбургского государственного университета, 2015(1), с. 250-255.

3. Chetverikova A. G., Filyak M. M., Kanygina O.N. Evolution of phase morphology in dispersed clay systems under the microwave irradiation. Ceramica, 2018, v. 64(371), pp. 367-372. DOI: 10.1590/036669132018643712354

4. Филяк М. М., Четверикова А. Г., Каныгина О. Н., Багдасарян Л. С. Фрактальный формализм в применении к анализу СВЧ-модификации нативной глины // Конденсированные среды и межфазные границы, 2016, т. 18(4), с. 578-585. URL: https://journals.vsu.ru/kcmf/article/view/168/94

5. Каныгина О. Н., Филяк М. М., Четверикова А. Г. Фазовые превращения в природной глине, обусловленные воздействием микроволнового излучения в воздушной и влажной средах // Неорганические материалы, 2018, т. 54(9), с. 955-960. DOI: $10.1134 / S 0002337 X 1809004 X$

6. Явна В.А., Каспржицкий А. С., Лазоренко Г. И., Кочур А. Г. Изучение ИК спектров полиминеральной природной ассоциации минералов класса филлосиликатов // Оптика и спектроскопия, 2015, т. $118(4)$, c. 558-565. DOI: $10.7868 /$ S0030403415040224

7. Четверикова А. Г., Каныгина О. Н., Филяк М. М., Савинкова Е. С. Оптико-физические методы регистрации слабых структурных откликов дисперсных глинистых систем на воздействие микроволнового излучения // Измерительная техника, 2017(11), с. 27-31.

8. Stevenson C. M., Gurnick M. Structural collapse in kaolinite, montmorillonite and illite clay and its role in the ceramic rehydroxylation dating of low-fired earthenware // Journal of Archaeological Science, 2016, v. 69, pp. 54-63. DOI: 10.1016/j.jas.2016.03.004

9. De Oliveira C. I. R., Rocha M. C. G., Da Silva A. L. N., Bertolino L. C. Characterization of bentonite clays from Cubati, Paraíba (Northeast of Brazil) // Ceramica, 2016, v. 62(363), pp. 272-277. DOI: 10.1590/0366-69132016623631970

10. Плюснина И. И. Инфракрасные спектры минералов. М.: Изд.-во Моск. ун-та, 1976, 190 с.

11. ГОСТ Р 56157-2014 Почва. Методики (методы) анализа состава и свойств проб почв. Общие требования к разработке. Введ. 01-07-2016. М.: Стандартинформ, 2015, с. 12.

12. Šaponjić A., Šaponjić Đ., Nikolić V, Milošević M., Marinović-Cincović M., Gyoshev S., Vuković M., Kokunešoski M. Iron (III) oxide fabrication from natural clay with reference to phase transformation $\gamma-\rightarrow$ $\alpha-\mathrm{Fe}_{2} \mathrm{O}_{3} / /$ Science of Sintering, 2017, v. 49(2), pp. 197205. DOI: $10.2298 /$ SOS1702197S 
13. Kool A., Thakur P., Bagchi B., Hoque N. A., Das S. Mechanical, dielectric and photoluminescence properties of alumina-mullite composite derived from natural Ganges clay // Applied Clay Science, 2015, v. 114, pp. 349-358. DOI: 10.1016/j.clay.2015.06.021

14. Stack K. M., Milliken R. E. Modeling near-infrared reflectance spectra of clay and sulfate mixtures and implications for Mars // Icarus, 2015, v. 250, pp. 332-356. DOI: 10.1016/j.icarus.2014.12.009

15. Anadro P., Pajolli I. L. R., Hildebrando E. A., Wiebeck H. Preparation and characterization of car- bon/montmorillonite composites and nanocomposites from waste bleaching sodium montmorillonite clay // Advanced Powder Technology, 2014,v. 25(3), pp. 926-932. DOI: 10.1016/j.apt.2014.01.010

16. Лазоренко Г. И., Каспржицкий А. С., Явна В.А. Применение методов ИК-спектроскопии для определения механических свойств поликристаллических материалов на основе слоистых алюмосиликатов // Конденсированные среды и межфазные границы, 2014, т. 16(4), с. 479-485. URL: http:// www.kcmf.vsu.ru/resources/t_16_4_2014_011.pdf

\title{
INFRARED SPECTROSCOPY AS THE METHOD FOR DETERMINING STRUCTURAL RESPONSES OF NATURAL CLAYS TO MICROWAVE EXPOSURE
}

\author{
(c) 2019 A. G. Chetverikova ${ }^{\bowtie}$, O. N. Kanygina, G. Zh. Alpysbaeva, A. A. Yudin, S. S. Sokabaeva \\ Orenburg State University \\ 13, Pobedy ave., 460018 Orenburg, Russian Federation
}

\begin{abstract}
Purpose. Universal applicability of naturally occurring materials such as clays attracts attention for scientific studies of their properties. In this paper microwave induced response of clay particles sourced in Orenburg region is studied. Infrared spectrometry method was used to control structural-morphological transformation induced by microwave field treatment in naturally occurring phyllosilicates. Properties of layered alumosilicates sourced from different deposits differ significantly from the standard samples. The goal of this paper is to study interatomic bounds evolution induced by microwave field treatment and to identify spectral modes in naturally occurring clays that contain montmorillonite and kaolinite with similar chemical composition, but different phase structures.

Methods and methodology. Clays containing more than $50 \%$ of montmorillonite and kaolinite were treated by $750 \mathrm{~W}$ microwave field for 10 minutes in two regimes. Chemical bound evolution was evaluated via infrared spectrometry of $\mathrm{KBr}$ samples pressed into pill form, measurements were performed with infrared Fourier spectrometer.

Results and conclusions. Infrared spectra of montmorillonite containing clay samples indicate existence of microwave induced structure changes. The spectral peak related with valence symmetric vibrations vanishes. Deformation unbridged bound $\mathrm{Al}-\mathrm{O}-\mathrm{H}$ (line $912 \mathrm{~cm}^{-1}$ ) vanishes after microwave treatment in dry air environment and reappears in a humid environment as $\mathrm{Si}-\mathrm{O}-\mathrm{Si}$ bound (line $1009 \mathrm{~cm}^{-1}$ ). Intensity of absorption lines related to valence vibration of $\mathrm{Si}-\mathrm{O}-\mathrm{Si}$ bound in $\mathrm{SiO}_{4}$ tetrahedron $\left(797 \mathrm{~cm}^{-1}\right)$ and deformation vibrations of $\mathrm{Si}-\mathrm{O}$ bounds in $\mathrm{SiO}_{4}$ tetrahedron $(533,467,428)$ are reduced by factors 1.5 and 1.8 correspondingly after microwave treatment in air and humid environments.

Infrared spectra of kaolinite clays contain absorption lines, $\mathrm{cm}^{-1}: 3620.3424,1032,1008$, and 912. Microwave treatment destroy the most part of bounds: in air environment their content is reduced by factor 1.8-2; in a humid environment by factor 2.5. Mainly dominate bounds in $\mathrm{SiO}_{4}$ tetrahedra and bounds $\delta(\mathrm{Al}-\mathrm{O}-\mathrm{H})$ are destroyed. Kaolinite clay is more susceptible to microwave treatment.
\end{abstract}

Keywords: infrared spectroscopy, absorption band, montmorillonite, kaolinite, phyllosilicates, microwave exposure, chemical bonds.

$\triangle$ Chetverikova Anna G, e-mail:kr-727@mail.ru 


\section{SOURCE OF FINANCING}

This work was supported by the RFBR grant No. 1943-560001 r_a a "Physico-chemical principles of microwave consolidation processes of kaolin clays from the Orenburg region as the electroporcelain basis".

\section{CONFLICT OF INTEREST}

The authors declare the absence of obvious and potential conflicts of interest related to the publication of this article.

\section{REFERENCES}

1. Domashevskaya, E. P., Builov, N. S., Lukin, A. N. Sitnikov A. V. IR spectroscopic study of interatomic interaction in $\left[(\mathrm{CoFeB}) 60 \mathrm{C} 40 / \mathrm{SiO}_{2}\right] 200$ and $\left[(\mathrm{CoFeB}) 34\left(\mathrm{SiO}_{2}\right) 66 / \mathrm{C}\right] 46$ multilayer nanostructures with metal-containing composite layers. Neorganicheskie materialy [Inorganic Materials], 2018, v. 54(9), pp. 140-146 DOI: 10.1134/S002016851802005X

2. Chetverikova, A. G., Maryakhina V. S. Studies of polymineral clay containing three-layer aluminosilicates by physical methods. Vestnik Orenburgskogo gosudarstvennogo universiteta, 2015, no. 1, pp. 250-255. (in Russ.)

3. Chetverikova A. G., Filyak M. M., Kanygina O. N. Evolution of phase morphology in dispersed clay systems under the microwave irradiation. Ceramica, 2018, v. 64(371), pp. 367-372. DOI: 10.1590/036669132018643712354

4. Filyak M. M., Chetverikova A. G., Kanygina O. N., Bagdasaryan L. S. Fractal formalism as applied to the analysis of the microwave modification of disperse systems. Kondensirovannye sredy i mezhfaznye granitsy [Condensed Matter and Interphases], 2016, v. 18(4), pp. 578-585.URL: https://journals.vsu.ru/kcmf/article/ view/168/94 (in Russ.)

5. Kanygina O. N., Filyak M. M., Chetverikova A. G. Microwave-Induced Phase Transformations of Natural Clay in Air and Humid Media. Neorganicheskie materially [Inorganic Materials], 2018, v. 54(9), pp. 904-909. DOI: $10.1134 /$ S0020168518090042

6. Yavna V. A., Kasprzhitskii A. S., Lazorenko G. I., Kochur A. G. Study of IR spectra of a polymineral natural association of phyllosilicate minerals. Optics and Spectroscopy, 2015, v. 118(4), pp. 526-536. DOI: 10.7868/S0030403415040224

7. Chetverikova A. G., Kanygina O. N., Filyak M. M., Savinkova E. S. Physical optics methods of recording weak structural responses of dispersed clay systems to the effect of microwave radiation. Measurement Techniques, 2018, v. 60(1)1, pp. 1109-1115. DOI: 10.1007/s11018-018-1326-4

8. Stevenson C. M., Gurnick M. Structural collapse in kaolinite, montmorillonite and illite clay and its role in the ceramic rehydroxylation dating of low-fired earthenware. Journal of Archaeological Science, 2016, v. 69, pp. 54-63. DOI: 10.1016/j.jas.2016.03.004

9. De Oliveira C. I. R., Rocha M. C. G., Da Silva A. L. N., Bertolino L. C. Characterization of bentonite clays from Cubati, Paraíba (Northeast of Brazil). Ceramica, 2016, v. 62, Iss. 363, pp. 272-277. DOI: 10.1590/0366-69132016623631970

10. Plyusnina, I. I. Infrakrasnye spektry mineralov [Infrared spectra of minerals]. Moscow, Moscow University Publ., 1976, 190 p. (in Russ.)

11. ISO 11464:2006 Soil quality - Pretreatment of samples for physico-chemical analysis, ISO STANDARD, 2006, $11 \mathrm{p}$.

12. Šaponjić A., Šaponjić Đ., Nikolić V, Milošević M., Marinović-Cincović M., Gyoshev S., Vuković M., Kokunešoski M. Iron (III) oxide fabrication from natural clay with reference to phase transformation $\gamma^{-} \rightarrow$ $\alpha-\mathrm{Fe}_{2} \mathrm{O}_{3} / /$ Science of Sintering, 2017, v. 49(2), pp. 197205. DOI: $10.2298 /$ SOS1702197S

13. Kool A., Thakur P., Bagchi B., Hoque N.A., Das S. Mechanical, dielectric and photoluminescence properties of alumina-mullite composite derived from natural Ganges clay. Applied Clay Science, 2015, v. 114, pp. 349-358. DOI: 10.1016/j.clay.2015.06.021

14. Stack K. M., Milliken R. E. Modeling near-infrared reflectance spectra of clay and sulfate mixtures and implications for Mars. Icarus, 2015, v. 250, pp. 332-356. DOI: 10.1016/j.icarus.2014.12.009

15. Anadro P., Pajolli I. L. R., Hildebrando E. A., Wiebeck H. Preparation and characterization of carbon/montmorillonite composites and nanocomposites from waste bleaching sodium montmorillonite clay. Advanced Powder Technology, 2014,v. 25(3), pp. 926-932. DOI: 10.1016/j.apt.2014.01.010

16. Lazorenko G. I., Kasprzhitskii A. S., Yavna V. A. Application of IR spectroscope to determine mechanical properties of polycrystalline materials based on layered aluminosilicate. Kondensirovannye sredy i mezhfaznye granitsy [Condensed Matter and Interphases], 2014, vol. 16, no. 4, pp. 479-485. URL: http://www.kcmf. vsu.ru/resources/t_16_4_2014_011.pdf (in Russ.)
Четверикова Анна Геннадьевна - к. ф.-м. н., доцент, декан физического факультета, Оренбургский государственный университет, Оренбург, Российская Федерация; e-mail: kr-727@ mail.ru. ORCID iD 0000-0002-7045-3588.
Chetverikova Anna G. - Cand. Sci. (Phys.Math.), Associate Professor, Dean of the Physics Department, Orenburg State University, Orenburg, Russian Federation; e-mail: kr-727@mail.ru. ORCID iD 0000-0002-7045-3588. 
Каныгина Ольга Николаевна - д. ф.-м. н, профессор, профессор кафедры физики и методики преподавания физики, Оренбургский государственный университет, Оренбург, Российская Федерация; e-mail: onkan@mail.ru. ORCID iD 00000001-6501-900X.

Алпысбаева Гульжазира Жанибековна - студент 4 курса кафедры химии, химико-биологический факультет, Оренбургский государственный университет, Оренбург, Российская Федерация; e-mail: qwertysimpleplan@mail.ru. ORCID iD 0000-0001-6066-9679.

Юдин Александр Андреевич - студент 4 курса кафедры химии, Оренбургский государственный университет, Оренбург, Российская Федерация; e-mail: yudin-s97@yandex.ru. ORCID iD 0000-0003-2424-0781.

Сокабаева Сания Серекбаевна - ведущий инженер кафедры биофизики и физики конденсированного состояния, Оренбургский государственный университет, Оренбург, Российская Федерация; e-mail: sania.sokabaeva@gmail. com. ORCID iD 0000-0003-0619-4363.
Kanygina Olga N. - Dr. Sci. (Phys.-Math.), Professor, Professor of the Department of Physics and Physics Teaching Methodology, Orenburg State University, Orenburg, Russian Federation; e-mail: onkan@mail.ru. ORCID iD 0000-0001-6501-900X.

Alpysbaeva Gulzhazira Zh. - 4th year student of the Department of Chemistry, Faculty of Chemistry and Biology, Orenburg State University, Orenburg, Russian Federation; e-mail: qwertysimpleplan@ mail.ru. ORCID iD 0000-0001-6066-9679.

Yudin Alexander A. - 4th year student of the Department of Chemistry, Orenburg State University, Orenburg, Russian Federation; e-mail: yudin-s97@yandex.ru. ORCID iD 0000-0003-24240781.

Sokabayeva Saniya Serekbayevna - Leading Engineer of the Department of Biophysics and Condensed Matter Physics, Orenburg State University, Orenburg, Russian Federation; e-mail: sania.sokabaeva@gmail.com. ORCID iD 0000-0003-06194363. 